\title{
Desenho e validação de um sistema de observação no Andebol
}

\author{
João Prudente ${ }^{1}$ \\ Júlio Garganta ${ }^{2}$ \\ Maria T. Anguera ${ }^{3}$
}

https://doi.org/10.5628/rpcd.04.03.49

\author{
${ }^{1}$ Departamento de Educação Física e Desporto \\ Universidade da Madeira, Portugal \\ ${ }^{2}$ Faculdade de Ciências do Desporto e de Educação Física \\ Universidade do Porto, Portugal \\ ${ }^{3}$ Faculdade de Psicologia, Universidade de Barcelona \\ Espanha
}

ABSTRACT
Design and validation of an observational system in Handball

O presente estudo dá conta dos passos seguidos na etapa preliminar de construção e validação de um sistema de observação ad hoc para o Andebol, com base na importância relativa atribuída a variáveis tácticas. Numa primeira fase foi realizado um levantamento das variáveis utilizadas em diferentes estudos levados a cabo no âmbito da análise do jogo de Andebol. De seguida procedeu-se à observação casuística de jogos de Andebol $(n=6)$ referentes aos Campeonatos da Europa 2002 e do Mundo 2003, no sentido de inventariar as variáveis que aparentassem mapear os aspectos nucleares do jogo. Do cruzamento da informação obtida a partir destes processos resultou a configuração do seguinte lote de variáveis: localização espacial da acção; relações guarda-redes/atacante com bola, defensor/atacante com bola e defensor/organização defensiva; recuperação da bola; desenvolvimento da sequência ofensiva; e finalização. Posteriormente, foi solicitado a um painel de peritos em Andebol $(n=9)$ que se pronunciasse sobre a pertinência destas variáveis, considerando a respectiva representatividade em relação aos aspectos fundamentais do jogo. Para o efeito, foi construído um questionário com escalas de resposta graduadas em cinco pontos (escala de Likert), do menos para o mais importante. As variáveis foram consideradas representativas sempre que mais de $65 \%$ dos treinadores (i.e., pelo menos seis dos nove inquiridos) situassem as respectivas respostas nos níveis quatro ou cinco da escala, já que o nível três correspondia a um valor neutro e os níveis um e dois equivaliam a valores não representativos. Os peritos elegeram, então, como variáveis mais representativas: a acção do guarda-redes (100\%); o remate $(89 \%)$; o contra-ataque $(89 \%)$; a defesa $(89 \%)$; o ataque em superioridade numérica (78\%); as assistências (78\%); e o jogo em desigualdade numérica (67\%). Daqui se infere que o sistema de observação mapeia aspectos fundamentais do jogo, e como tal pode ser utilizado para estudar aspectos relevantes da dinâmica da performance individual e das equipas em cada jogo e ao longo de diferentes jogos.

Palavras-chave: análise do jogo, metodologia observacional, sistema de observação, andebol.
This study aims at presenting all steps involved in a preliminary design and content validity of an ad hoc observational system in handball. It is based, mainly, in the relative importance of tactical variables. In phase 1, an inventory was made concerning all variables used in previous published papers, master and Ph.D. thesis related to handball game in competitive settings. In phase 2, a "simple structure observation" was used in 6 handball games in European (2002) and World (2003) championships. Main emphasis was on an exhaustive inventory of all variables that were thought to map important game aspects. Crossing all relevant information from these two phases, it was possible to derive the following set of configuration variables: special location of main actions; relationship between goal-keeper and attacker with the ball; defender with attacker having the ball; defender/defensive organization; ball recovering; development of offensive sequences; finalization (this was phase 3). In phase 4, we asked an expert panel $(n=9)$ to critically review and analyze main conclusions from phase 3. We have also asked for precise answers, from irrelevant to most important, to all game actions defined in phase 3. Main results from this panel of answers were: goal-keeper actions (100\% agreement), shots to goal (89\%), counter-attack (89\%), defense (89\%), attack in numeric superiority (78\%), assists (78\%), and game in numeric inequality (67\%). The main conclusion is that the ad hoc observational system seems to map the most important aspects of the game. Therefore it is a relevant instrument to study the dynamics of players' and teams' performance over time.

Key Words: match analysis, observational methodology, observation system, handball. 


\section{INTRODUÇÃO}

O contexto no qual tem lugar a actividade desportiva é vasto e abrangente $(17,5)$. Nele concorrem actividades, situações, rotinas, interacções, estratégias e tácticas, cujo conhecimento e compreensão resultam essenciais para descrever, compreender e analisar o comportamento desportivo $(16,5)$.

O Andebol é uma modalidade desportiva com uma grande implantação internacional e para cuja expansão contribuiu de forma decisiva a sua inclusão como modalidade olímpica nos J.O. de Munique em 1972.

Foi assim com naturalidade que se assistiu ao aparecimento de publicações e trabalhos de investigação científica tendo por objecto de estudo esta modalidade, procurando um aumento de conhecimentos acerca da mesma.

Segundo Garganta (12), para obter um conhecimento da modalidade e da importância de cada elemento para o resultado da competição, os treinadores e outros especialistas recorrem à análise do jogo, entendida como o estudo do jogo a partir da observação da actividade dos jogadores e das equipas, o que tem vindo a constituir um argumento de crescente importância nos processos de preparação desportiva. Tal importância pode ser explicada pelas virtualidades que se lhe reconhece, traduzidas, quer no aporte de informação que daí pode resultar para o treino, quer nas potenciais vantagens que encerra para viabilizar a regulação da prestação competitiva (11). Através da análise do jogo, tradicionalmente, tem-se estudado as interacções entre os jogadores e os seus movimentos e comportamentos individuais - maioritariamente habilidades abertas. Estes estudos, centrando-se nos indicadores de jogo gerais, tácticos e técnicos, têm contribuído para o nosso conhecimento sobre as exigências fisiológicas, psicológicas, técnicas e tácticas de muitas modalidades desportivas (18). Isto mesmo é sustentado por Lames \& Hansen (20), que referem como objectivos da análise do jogo, utilizando sistemas observacionais: medir a performance individual, as cargas físicas, as soluções tácticas para situações especiais, o estudo das interacções inter e intra equipas, a descoberta de talentos, apoiar a tomada de decisão dos treinadores e o interesse teórico na estrutura dos jogos.

Este aumento de conhecimentos permite a com- preensão do desenvolvimento do jogo e do treino, e passa, invariavelmente, pela identificação de comportamentos que testemunham a eficiência e a eficácia dos jogadores e das equipas (11). E passa, ainda, por um âmbito mais vasto que engloba, entre outros, a procura de indicadores prospectivos ou retrospectivos de condutas de êxito ou fracasso, o estudo direccional das relações interpessoais de emissão ou recepção no seio de uma equipa, e o estudo da mutação de padrões de conduta em acções de jogo ofensivas, segundo as características da equipa adversária (5).

Ao pensar-se na recolha da informação para analisar o jogo, convém não ignorar a existência das chamadas estatísticas oficiais nas principais competições, ainda que as mesmas procurem satisfazer necessidades particulares de informação de treinadores e comunicação social. Habitualmente, durante a competição são recolhidos variados dados estatísticos que fornecem informação sobre o número de posses de bola, o número de ataques, o número de remates, os golos marcados e sofridos, as defesas do guardaredes, o número de exclusões, entre outros, e que são distribuídos aos treinadores e imprensa.

Anguera et al. (6) questionam o modo como são recolhidos tais dados, e portanto a sua fidelidade, situando-nos assim ante aquilo que designam como questões-chave da observação, uma das quais se prende com a compatibilidade "Técnica de observação" versus "Metodologia observacional".

Sendo a metodologia observacional uma das opções de estudo científico do comportamento humano (6), o objectivo deste artigo é dar a conhecer os passos para a construção de um sistema de observação em Andebol e ilustrar os caminhos seguidos para a respectiva validação. Trata-se de configurar um sistema que permita registar, de forma fidedigna, os comportamentos dos jogadores e equipas da elite mundial do Andebol masculino, durante as sequências ofensivas, a partir da observação sistemática dos jogos do Campeonato da Europa de 2002 e do Campeonato do Mundo de 2003.

Os passos dados para a construção do sistema de observação, bem como os caminhos seguidos para a sua validação podem traduzir-se de forma esquemática conforme Fig. 1. 


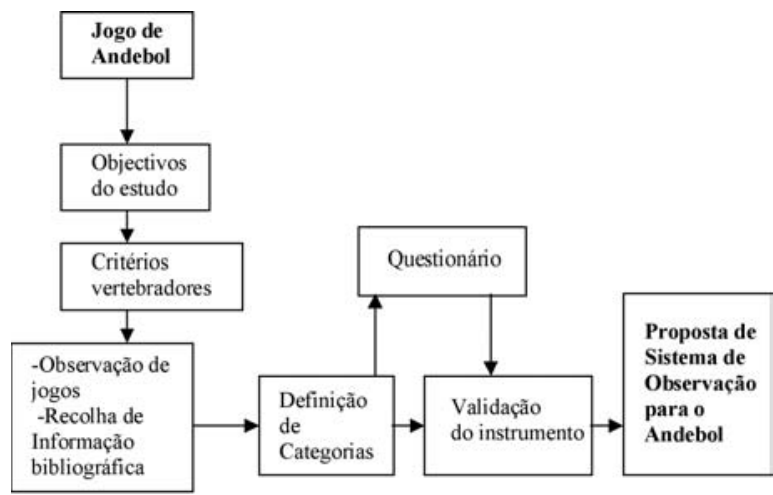

Fig. 1 - Esquema do trabalho a desenvolver

A recolha e posterior tratamento dos dados permitirão analisar diferentes indicadores táctico-técnicos e a sua influência no resultado final.

O recurso à análise sequencial possibilitará a detecção de padrões de conduta, bem como a procura de relações de associação significativas entre condutas, registadas durante as referidas sequências. A análise de coordenadas polares dará origem a uma representação vectorial da complexa rede de inter-relações que se estabelecem entre as diferentes categorias que constituem o sistema a utilizar (7).

\section{ELABORAÇÃO DO INSTRUMENTO DE OBSERVAÇÃO}

Neste artigo recorremos à metodologia observacional, considerando que a mesma tem como objecto de estudo o indivíduo (perspectiva ideográfica) inserido num determinado contexto. No caso presente, tratase de um jogo de Andebol, mas o indivíduo em estudo pode também representar uma unidade de observação (conjunto de avançados no Futebol; equipa de Andebol, etc.). A observação e registo do seu comportamento é realizada através de um instrumento elaborado ad hoc, sendo preferível que possa ser seguido de forma diacrónica, ou seja, ao longo de um tempo relativamente prolongado (treino, competição, etc.), como referem Anguera et al. (6). O processo metodológico da observação é "um procedimento destinado a articular uma percepção deliberada da realidade manifesta com a sua adequada interpretação, captando o seu significado, de forma que mediante um registo objectivo, sistemático e específico da conduta gerada de forma espontânea num determinado contexto, e uma vez que se tenha submetido a uma adequada codificação e análise, nos proporciona resultados válidos dentro de um marco específico de conhecimento" $(1,15)$.

Esta metodologia, com uma expansão inegável nas últimas décadas e cujo carácter científico se encontra perfeitamente avalizado conforme nos referem Anguera et al. (6), requer o cumprimento de alguns requisitos básicos: a espontaneidade do comportamento, que este ocorra num contexto natural (neste caso no terreno de jogo de Andebol), que seja um estudo prioritariamente ideográfico, que o instrumento de observação seja elaborado ad hoc, que se garanta continuidade temporal e que o comportamento seja perceptível.

Acresce que no âmbito desportivo estamos perante uma situação social em mudança permanente, pelo que os procedimentos estáticos de análise não são suficientes, antes requerem uma perspectiva dinâmica das condutas, o que coloca a metodologia observacional como ferramenta mais adequada (15). De facto, nos jogos desportivos, como é o caso do Andebol, o quadro do jogo é organizado e conhecido mas o seu conteúdo é sempre imprevisível e aleatório (11). Não obstante o peso do factor aleas, as acções de jogo são "categorizáveis”, isto é, reconvertíveis em categorias ou tipos de ocorrências, que constituem unidades de acção (13).

A diversidade de situações susceptíveis de serem sistematicamente observadas no comportamento desportivo, obriga a prescindir de instrumentos estandardizados e, pelo contrário, a dedicar o tempo necessário a prepará-los ad hoc de acordo com contextos específicos. Existem como instrumentos básicos da metodologia observacional, o sistema de categorias e o formato de campo, a que se incorpora, de forma residual, a rating scale. $\mathrm{O}$ sistema de categorias tem um estatuto mais elevado pelo seu imprescindível suporte teórico, enquanto os formatos de campo constituem um instrumento mais flexível, especialmente adequado em situações empíricas de elevada complexidade e com um marco teórico débil (5). Anguera (4), afirma ser recomendável juntar um ou mais sistemas de categorias num ou mais critérios, ou macro-categorias, dos formatos de campo, de maneira que a relação de condutas/situações que 
correspondem a este(s) critério(s) seriam as categorias que conformam o sistema, mantendo-se estas exaustivas e mutuamente exclusivas a nível intra critério do formato de campo.

Dado que a observação nos permite descrever objectivamente a realidade para analisá-la, a delimitação dos objectivos torna-se necessária e tem a função de delimitar a parcela de realidade que nos interessa (3). Assim, antes de estabelecermos as macro-categorias do nosso instrumento de observação, tivemos em conta os objectivos do nosso estudo: (i) Determinar padrões sequenciais realizados pelas equipas nas fases ofensiva e defensiva e relacioná-los com o resultado final, considerando as situações de desigualdade numérica mínima e máxima no Andebol mundial de alto nível; (ii) Analisar os livres de 9 metros, considerando a forma como o ataque se desenvolve a partir destas situações especiais de jogo e como a defesa se opõe e organiza face às mesmas, e relacionar as respectivas características com o resultado final; (iii) Analisar a acção do guardaredes, tanto nas situações de confronto directo com o rematador, como nas situações em que existe cooperação defensor/guarda-redes na defesa do remate, relacionando as respectivas características com o resultado final; (iv) Analisar a acção de remate no livre de 7 metros e a sua relação com o resultado final; (v) Analisar o método de jogo ofensivo contraataque e a sua relação com o resultado final.

Definidos os objectivos, acima mencionados, partimos para a construção do sistema de observação, optando pelo formato de campo com sistemas de categorias, tendo em vista manter a maior flexibilidade dos formatos de campo, incorporando-se em cada critério categorias rígidas que representam o desenvolvimento de cada um deles (4).

Seguindo os passos metodológicos para a elaboração do formato de campo (6), em primeiro lugar definimos os critérios vertebradores do instrumento e em segundo lugar, através de uma fase exploratória, realizámos uma listagem não fechada de condutas/situações observadas, correspondentes a cada critério.

Esta fase exploratória do estudo, efectuada através da observação de imagens vídeo referentes a jogos $(n=6)$ do Campeonato Europeu de Andebol de 2002 e do Campeonato do Mundo de Andebol de 2003, incidiu sobre as sequências ofensivas observa- das nos referidos jogos.

Tal procedimento permitiu-nos uma familiarização com a situação e com os comportamentos desportivos que são objecto do nosso estudo, indo ao encontro da perspectiva de Anguera (4), quando a autora refere ser recomendável, antes de iniciar um estudo sistemático, dedicar umas sessões à fase exploratória ou passiva, a qual, apesar de ter um carácter assistemático ou casual, é de grande utilidade. Neste sentido, as principais finalidades desta fase são: a) Contribuir para delimitar de forma precisa o objecto de estudo; b) Diminuir ou eliminar a possibilidade do sujeito observado modificar a sua conduta espontânea pelo facto de sentir-se observado; c) Aumentar o nível de treino do observador; d) Recolher suficiente informação que permita adoptar, a posteriori e no início da fase activa ou científica da observação, as decisões mais acertadas (sobre o plano da amostra, tipo de registo mais adequado, etc.).

Elegemos as macro-categorias ou critérios axiais do sistema, em função dos objectivos do nosso estudo, e numa lógica de leitura do jogo, desde a finalização da sequência ofensiva anterior, passando pela recuperação da bola, pelo desenvolvimento de nova sequência e sua finalização.

A justificação da sua elegibilidade é a seguinte: considerámos a localização espacial pela necessidade de contextualizar onde ocorrem as acções; a relação guarda-redes/atacante com bola porque nos permite analisar o guarda-redes, não de uma forma isolada, mas em confronto com o rematador e considerando a acção do defensor; a relação defensor/atacante com bola porque nos permite analisar o rematador tendo em conta a acção do defensor; a relação defensor/ organização defensiva porque nos permite contextualizar o comportamento do defensor no seu confronto com o atacante com bola; a recuperação da bola porque nos permite analisar o modo como é feita e por quem (guarda-redes ou jogador de campo), o que se torna necessário para compreender o modo como se inicia o desenvolvimento da sequência; o desenvolvimento da sequência que nos permite analisar como se inicia e como se desenrola o processo ofensivo; e, por último, a finalização que nos permite a recolha de informação sobre como ocorre o final da sequência ofensiva: o que a precede em termos de meios utilizados para romper o equilíbrio ataque/defesa, em que contexto ocorre (organizações de jogo ofensivo e 
defensivo em confronto, resultado e tempo de jogo) e o modo como é concluída a sequência ofensiva.

Relativamente aos indicadores, ou categorias observáveis, utilizados, foram por nós elegidos com base na recolha bibliográfica e na experiência pessoal enquanto treinador de Andebol (ver Quadro 1). No Andebol é atribuída particular relevância aos indicadores de rendimento que expressam a eficácia dos jogadores e o seu contributo para a prestação colectiva (23). Desses indicadores podemos seleccio- nar alguns que, segundo diversos autores, são determinantes para a compreensão da prestação das equipas, separando-os em três áreas distintas: indicadores referentes à relação existente entre remates efectuados e golos alcançados por zona e método de jogo (22); indicadores referentes ao comportamento defensivo das equipas e em particular do guardaredes $(9,22)$; e, por último, indicadores referentes às situações de jogo em desigualdade numérica $(8,9,24)$.

Quadro 1. Macro-categorias e indicadores propostos.

\begin{tabular}{|c|c|}
\hline MACRO-CATEGORIAS & INDICADORES \\
\hline \multirow[t]{2}{*}{ Localização espacial } & - Localização espacial da baliza \\
\hline & - Localização espacial do campo \\
\hline \multirow[t]{4}{*}{ Guarda-Redes / Atacante com bola } & - Localização do atacante \\
\hline & - Acção de remate \\
\hline & - Acção do guarda-redes \\
\hline & - Colaboração com defensor \\
\hline \multirow[t]{3}{*}{ Defensor / Atacante com bola } & - Posição do defensor \\
\hline & - Tipo de oposição: - Passiva \\
\hline & - Activa \\
\hline \multirow[t]{4}{*}{ Defensor /Organização defensiva } & - Sistema defensivo \\
\hline & - Tipo de actuação defensiva \\
\hline & - Posto específico \\
\hline & - Relação numérica \\
\hline \multirow[t]{5}{*}{ Recuperação da bola } & - Jogador que recupera : - Guarda-redes \\
\hline & - Defensores \\
\hline & - Início da sequência: - Zona de início \\
\hline & - Modo de início \\
\hline & - Jogador que inicia \\
\hline \multirow[t]{8}{*}{ Desenvolvimento } & - Trajectória da bola: $-n^{0}$ de passes \\
\hline & $-n^{0}$ de jogadores \\
\hline & - Corredores utilizados \\
\hline & - Método de jogo \\
\hline & - Relação numérica ataque/defesa \\
\hline & - Duração da sequência \\
\hline & - Tempo de jogo decorrido \\
\hline & - Resultado \\
\hline \multirow[t]{8}{*}{ Finalização } & - Localização \\
\hline & - Meios tácticos \\
\hline & - Organização defensiva adversária \\
\hline & - Organização ofensiva \\
\hline & - Modo de conclusão: - Com remate \\
\hline & -Sem remate \\
\hline & - Marcador: - Resultado após a sequência ofensiva \\
\hline & - Tempo de jogo decorrido após a sequência ofensiva \\
\hline
\end{tabular}




\section{VALIDAÇÃO DO SISTEMA DE OBSERVAÇÃO}

Segundo Anguera (2), observar depende da interacção de três elementos fundamentais: a percepção, a interpretação e o conhecimento prévio. Dado que nenhuma observação pode ser considerada perfeita, devido às distorções sistemáticas e assistemáticas introduzidas pelos erros dos próprios observadores e pelo próprio procedimento, justifica-se a introdução, na expressão $\mathrm{O}$ (observação) $=\mathrm{P}($ percepção $)+\mathrm{I}$ (interpretação) + Cp (conhecimento prévio), de um elemento corrector (D), relativo ao desvio no processo observacional. A representação passará a ser a seguinte:

$$
\mathrm{O}=\mathrm{P}+\mathrm{I}+\mathrm{Cp}-\mathrm{D} \text {. }
$$

Este facto permite-nos afirmar que o processo inerente à observação implicará operações próprias de cada observador, baseadas no quadro de referências que cada um possui, tornando-se pessoal (21). Contudo, a pesquisa científica tem na replicabilidade uma das suas características, isto é, toda a investigação deve poder ser reproduzida.

Para superar este carácter individual, garantindo a possibilidade de replicação do estudo, para além da explicitação dos passos metodológicos adoptados na elaboração do instrumento de observação, torna-se necessário garantir que o instrumento permita observar aquilo que realmente se pretende observar. A validação do sistema de observação é pois um dos passos metodológicos a realizar.

Deste modo, procura-se respeitar a validade de conteúdo, de maneira a verificarmos o grau de cobertura do instrumento, e a validade de constructo, que permite verificar se os indicadores propostos descrevem efectivamente o rendimento no Andebol.

Como procedimento de validação, de conteúdo e de constructo, decidimos recorrer, através de um questionário, ao acordo de um grupo de peritos em Andebol: treinadores das Ligas de Andebol de Portugal e investigadores das Ciências do Desporto da área do Rendimento Desportivo/Andebol.

\section{ELABORAÇÃO DO QUESTIONÁRIO}

O questionário constitui uma das técnicas disponíveis para a obtenção de dados na pesquisa social, podendo definir-se "como a técnica de investigação composta por um número mais ou menos elevado de questões apresentadas por escrito às pessoas, tendo por objectivo o conhecimento de opiniões, crenças, sentimentos, interesses, expectativas, situações vivenciadas, etc. (14).

Os passos metodológicos seguidos na elaboração do questionário foram os seguintes: (i) Pesquisa bibliográfica, com o objectivo de efectuar um rigoroso levantamento dos indicadores de rendimento utilizados nos diferentes trabalhos até hoje efectuados, no âmbito da análise do rendimento no Andebol; (ii) Análise da importância atribuída aos diferentes factores do treino do Andebol, através da consulta, que se procurou exaustiva, de diferentes manuais de treino da modalidade; (iii) Fase exploratória do estudo, com realização de diversas sessões de observação de jogos do Campeonato da Europa de 2002 e do Campeonato do Mundo de 2003, tendo em conta os objectivos do trabalho e os critérios definidos; (iv) Elaboração de um sistema de observação misto de formato de campo com sistemas de categorias, com base na pesquisa bibliográfica efectuada e nos dados recolhidos na fase exploratória do estudo, sendo estes passos necessários para a construção do questionário; (v) Elaboração do questionário.

O questionário foi construído de modo a divulgar os objectivos pretendidos, permitir a recolha de dados pessoais dos inquiridos, a recolha da opinião sobre os indicadores de rendimento e sobre a adequação das variáveis à análise do rendimento de uma equipa de Andebol. Ficou estruturado do seguinte modo: (i) Introdução, com a explicação do fim a que se destina, quais os objectivos pretendidos e o agradecimento da colaboração; (ii) Uma parte inicial destinada à recolha de dados pessoais que permitissem caracterizar os especialistas inquiridos do ponto de vista da idade, vivências da modalidade, experiência profissional, nível de formação académica e nível de formação como treinador, com um total de seis questões; (iii) Uma primeira parte, baseada nos indicadores de rendimento recolhidos da bibliografia utilizada, com nove questões principais, destinada a auscultar a opinião sobre o grau de importância atribuída a cada um dos indicadores, incluindo uma questão aberta, para os especialistas indicarem e classificarem de igual modo, outros indicadores que considerassem existirem; (iv) Uma segunda parte, baseada no sistema de observação construído na sequência da fase exploratória do estudo, com seis questões principais relati- 
vas às seis macro - categorias definidas para o formato de campo, onde se solicitava que os especialistas se pronunciassem sobre a adequação das variáveis para analisar o rendimento e que incluía uma questão aberta para que, indicando o grau de importância que lhe atribuíam, indicassem outras variáveis que devessem ser incluídas no estudo.

Depois de redigido o questionário e antes do mesmo ser aplicado, realizámos um pré-teste com o objectivo de "evidenciar possíveis falhas na redacção, tendo em vista avaliar a validade e precisão do mesmo" (14), ou seja, verificar de acordo com este autor: (i) A clareza e precisão dos termos; (ii) A forma das questões; (iii) O desmembramento das questões; (iv) A ordem das questões; e (v) A introdução do questionário.

Para este pré - teste foram seleccionados treinadores de Andebol, antigos praticantes, licenciados em Educação Física e Desporto, com a opção de Andebol.

Estes treinadores preencheram os inquéritos e, após o seu preenchimento, reuniram individualmente connosco, tendo-se abordado as dúvidas e dificuldades que o seu preenchimento havia suscitado. As respostas permitiram precisar os termos de algumas questões, tornando mais claro o que se pretendia com cada uma delas.

Para graduar as opiniões dos inquiridos decidimos utilizar uma escala de Likert, de graduação de carácter ordinal de 1 a 5 .

\section{APLICAÇÃO DO QUESTIONÁRIO E ANÁLISE DOS RESULTADOS}

Concluído o questionário, e efectuado o pré-teste, procedeu-se à sua reformulação tendo em conta as opiniões e dificuldades sentidas pelos inquiridos, após o que se considerou estar este instrumento em condições de ser utilizado.

O questionário foi distribuído a nove especialistas, tendo estes sido previamente contactados, no sentido de lhes ser pedida a colaboração, e explicado e prestados todos os esclarecimentos sobre o mesmo e sobre os objectivos do trabalho.

Destes nove especialistas fazem parte: a totalidade dos investigadores que nas universidades públicas portuguesas estudam o Andebol, têm trabalhos publicados e são treinadores e ainda todos os treinadores da Liga Profissional de Andebol de Portugal que cumulativamente são licenciados em Educação Física e têm uma formação pós-graduada no âmbito das Ciências do Desporto - Andebol.

Importa referir não haver em Portugal, no momento da elaboração do questionário, mais nenhum especialista que reunisse cumulativamente estas características. Integra ainda a amostra, um treinador estrangeiro com uma ampla bibliografia sobre andebol já publicada, com uma grande experiência profissional ao mais alto nível e doutorado em Ciências do Desporto, com um estudo realizado no âmbito dos aspectos tácticos do Andebol. Após a recolha dos questionários procedemos ao tratamento e análise dos resultados obtidos (ver Quadros 2 a 6).

Quadro 2. Caracterização da amostra inquirida.

\begin{tabular}{|c|c|c|c|c|c|c|c|c|c|}
\hline Id. & Idade & Lic.E.F & Mestre & Doutor & Outra & Anos Treinador & $\begin{array}{c}\text { Nível } \\
\text { Treinador }\end{array}$ & $\begin{array}{l}\text { Antigo } \\
\text { Jogador }\end{array}$ & Int. \\
\hline A & 56 & \multirow{6}{*}{$\mathrm{x}$} & $x$ & & \multirow{9}{*}{$x$} & 25 & $2^{0}$ & $\mathrm{x}$ & $x$ \\
\hline B & 41 & & & & & 22 & $2^{0}$ & $x$ & \\
\hline C & 37 & & & & & 19 & $2^{\circ}$ & $\mathrm{x}$ & \\
\hline D & 48 & & $x$ & & & 10 & $2^{0}$ & $\mathrm{x}$ & \\
\hline$E$ & 33 & & $x$ & & & 5 & $2^{\circ}$ & $x$ & \\
\hline $\mathrm{F}$ & 49 & & $x$ & & & 15 & Nacional* & $\mathrm{x}$ & $x$ \\
\hline G & 41 & $x$ & & & & 20 & $2^{\circ}$ & $x$ & \\
\hline H & 51 & $x$ & & & & 15 & $2^{0}$ & $x$ & \\
\hline 1 & 55 & & & $x$ & & 29 & Mérito** & $x$ & $x$ \\
\hline Média & $45, ?$ & & & & & 17,8 & & & \\
\hline
\end{tabular}

Legendas: Id.- identificação; Lic.E.F.- Licenciatura em educação Física e Desporto; Int. - jogador internacional;

* Treinador Nacional de Espanha; ** Treinador de Mérito de Espanha. 


\section{GRAU DE IMPORTÂNCIA ATRIBUÍDA AOS DIFERENTES INDICADORES DE RENDIMENTO}

Para analisarmos esta questão, considerámos apenas os graus " 4 - muito importante" e " 5 - bastante importante", já que numa escala de cinco graus, o central corresponde a uma posição indefinida (14). Solicitados a dar uma opinião sobre a importância atribuída aos diferentes factores técnico-tácticos para analisar o rendimento das equipas, os inquiridos pronunciaram-se, com total unanimidade, no que respeita à importância da eficácia do guarda-redes, considerando este indicador de "bastante importante". Outros indicadores como "eficácia no remate", "eficácia no contra-ataque" e "eficácia na defesa" obtiveram resultados muito significativos $(88,9 \%)$. De acordo com o critério utilizado e considerando como valor de corte $>65 \%$, valor que convencionámos e correspondente a seis de nove especialistas, apenas sete dos catorze factores técnico-tácticos considerados, foram classificados como "muito" ou "bastante importante" para a análise do rendimento.

Quadro 3- Grau de importância atribuído aos diferentes indicadores. Indicadores considerados mais importantes.

\begin{tabular}{|c|c|c|c|}
\hline Indicador & $\begin{array}{l}\text { 4-Muito } \\
\text { importante }\end{array}$ & $\begin{array}{l}\text { 5-Bastante } \\
\text { importante }\end{array}$ & $\begin{array}{c}\text { \% de opiniōes de grau } 4 \text { e } 5 \text { sobre } 0 \\
\text { total de inquiridos }\end{array}$ \\
\hline Eficácia do guarda-redes & & 9 & $100 \%$ \\
\hline Eficácia no remate & 1 & $?$ & $88,9 \%$ \\
\hline Eficácia no contra-ataque & 2 & 6 & $88,9 \%$ \\
\hline Eficácia na defesa & 2 & 6 & $88,9 \%$ \\
\hline Eficácia ataque em superi. numérica & 4 & 3 & $77,8 \%$ \\
\hline Eficácia nas assistências & 4 & 3 & $77,8 \%$ \\
\hline Eficácia no jogo em desigualdade numérica & 5 & 1 & $66,7 \%$ \\
\hline
\end{tabular}

Solicitados a dar a sua opinião sobre a importância atribuída a diferentes factores, para analisar o rendimento das equipas no jogo em desigualdade numérica, os especialistas destacaram o comportamento das equipas durante os períodos de jogo (ataque/defesa) em superioridade numérica e a eficácia no ataque em superioridade numérica, como sendo os principais factores para analisar rendimento em situações de desigualdade numérica.

Quadro 4 - Importância dos factores na análise do rendimento no jogo em desigualdade numérica.

\begin{tabular}{|c|c|c|c|}
\hline Indicador & $\begin{array}{l}\text { 4-Muito } \\
\text { importante }\end{array}$ & $\begin{array}{l}\text { 5-Bastante } \\
\text { importante }\end{array}$ & $\begin{array}{l}\% \text { de opiniões de grau } 4 \text { e } 5 \\
\text { sobre o total de inquiridos }\end{array}$ \\
\hline Eficácia no ataque em superioridade numérica & 2 & 6 & $88,9 \%$ \\
\hline $\begin{array}{l}\text { Comportamento durante os períodos de jogo (ataque/defesa) } \\
\text { em superioridade numérica }\end{array}$ & 4 & 4 & $88,9 \%$ \\
\hline Eficácia na defesa em superioridade numérica & 1 & 6 & $77,8 \%$ \\
\hline Eficácia na defesa em inferioridade numérica & 4 & 3 & $77,8 \%$ \\
\hline $\begin{array}{l}\text { Comportamento durante os períodos de jogo [ataque/defesa] } \\
\text { em inferioridade numérica }\end{array}$ & 4 & 3 & $77,8 \%$ \\
\hline Eficácia no ataque em inferioridade numérica & 3 & 3 & $66,7 \%$ \\
\hline
\end{tabular}


Com o objectivo de verificar se consideravam de modo diferente a importância da eficácia no jogo em superioridade numérica relativamente à eficácia no jogo em inferioridade numérica, em relação à influência no resultado final, questionámos os especialistas. As respostas obtidas permitiram identificar uma tendência em dar mais importância à eficácia em superioridade numérica, como podemos verificar no Quadro 5.

Quadro 5 - Influência sobre o resultado final, da importância das eficácias em superioridade e inferioridade numérica, analisadas comparativamente.

\begin{tabular}{l|c|c|c}
\multicolumn{1}{c|}{ Indicador } & 4-Muitas vezes & 5-Sempre & $\%$ \\
\hline $\begin{array}{l}\text { Eficácia em } \\
\text { superioridade }\end{array}$ & 3 & 3 & $66,7 \%$ \\
$\begin{array}{l}\text { numérica } \\
\begin{array}{l}\text { Eficácia em } \\
\text { inferioridade } \\
\text { numérica }\end{array}\end{array}$ & 5 & 0 & $55,6 \%$ \\
\end{tabular}

$\mathrm{O}$ resultado do marcador e o tempo de jogo, são apontados com regularidade como elementos importantes a influenciar o resultado final dos jogos. A referência em diferentes manuais de treino, bem como em entrevistas de treinadores, à importância de gerir o tempo e o resultado é uma realidade. Pusemos a questão aos especialistas e solicitámos que se pronunciassem sobre se o resultado do marcador influenciava a eficácia ofensiva e a eficácia defensiva. As respostas obtidas confirmaram a importância do factor resultado do marcador, tanto para a eficácia defensiva como para a eficácia ofensiva. Já relativamente à influência do factor "tempo de jogo decorrido", apenas é reconhecida a influência que este exerce sobre a eficácia ofensiva, isto de acordo com o critério que definimos para o valor de corte (> 65\%).

Quadro 6 - Influência dos factores resultado do marcador e tempo de jogo decorrido, sobre as eficácias ofensiva e defensiva.

\begin{tabular}{|c|c|c|c|}
\hline $\begin{array}{c}\text { Factor } \\
\text { resultado }\end{array}$ & $\begin{array}{l}\text { 4- Muitas } \\
\text { vezes }\end{array}$ & 5-Sempre & $\%$ \\
\hline $\begin{array}{l}\text { Eficácia } \\
\text { defensiva }\end{array}$ & 5 & 2 & $77,8 \%$ \\
\hline $\begin{array}{l}\text { Eficácia } \\
\text { ofensiva }\end{array}$ & 7 & 0 & $77,8 \%$ \\
\hline $\begin{array}{l}\text { Factor } \\
\text { tempo }\end{array}$ & $\begin{array}{l}\text { 4- Muitas } \\
\text { vezes }\end{array}$ & 5-Sempre & $\%$ \\
\hline $\begin{array}{l}\text { Eficácia } \\
\text { defensiva }\end{array}$ & 5 & 0 & $55,6 \%$ \\
\hline $\begin{array}{l}\text { Eficácia } \\
\text { ofensiva }\end{array}$ & 5 & 1 & $66,7 \%$ \\
\hline
\end{tabular}

Na segunda parte do questionário solicitámos aos especialistas que se pronunciassem acerca da adequação das categorias observáveis ou indicadores, propostas no nosso sistema de observação, para analisar o rendimento de uma equipa na competição. Tendo como critério o valor de corte de $>65 \%$, equivalente a seis de entre nove especialistas questionados e considerando os graus 4 ("muito adequado") e 5 ("bastante adequado"), os resultados obtidos foram os seguintes, para cada indicador de cada um das macro-categorias (ver Quadros 7 a 12):

Quadro 7-Macro-categoria guarda-redes/atacante com bola.

\begin{tabular}{l|c|c|c}
\multicolumn{1}{c|}{ Indicador } & $\begin{array}{c}\text { 4- Muito } \\
\text { Adequado }\end{array}$ & $\begin{array}{c}\text { 5- Bastante } \\
\text { adequado }\end{array}$ & \% \\
\hline Localização do atacante & 3 & 5 & $88,9 \%$ \\
Acção de remate & 1 & 3 & $44,4 \%$ \\
Acção do guarda-redes & 6 & 3 & $100 \%$ \\
na defesa da baliza & & & $88,9 \%$ \\
Colaboração guarda- & 4 & 4 &
\end{tabular}

A adequação do indicador acção do guarda-redes na defesa da baliza, está estreitamente relacionada tanto com a localização do atacante como com a colaboração existente entre o guarda-redes e o defensor. Assim, percebe-se o facto de os especialistas terem considerado estes três indicadores adequados para analisar o rendimento do guarda-redes, valorizando-os em detrimento da acção de remate.

Quadro 8-Macro-categoria defensor/atacante com bola.

\begin{tabular}{l|c|c|c}
\multicolumn{1}{c|}{ Indicador } & $\begin{array}{c}\text { 4-Muito } \\
\text { Adequado }\end{array}$ & $\begin{array}{c}\text { 5-Bastante } \\
\text { adequado }\end{array}$ & $\%$ \\
\hline $\begin{array}{l}\text { Posição do } \\
\text { defensor face ao } \\
\text { atacante }\end{array}$ & 3 & 5 & $88,9 \%$ \\
$\begin{array}{l}\text { (proximidade) } \\
\text { Tipo de oposição }\end{array}$ & 4 & 3 & $? 7,8 \%$
\end{tabular}

Analisar a relação defensor/atacante com bola, considerada adequada pelos inquiridos, nos parâmetros de proximidade e tipo de oposição, permite-nos completar a informação do quadro anterior relativa à colaboração guarda-redes/defensor. 
Quadro 9 - Macro-categoria defensor/organização defensiva.

\begin{tabular}{l|c|c|c}
\multicolumn{1}{c|}{ Indicador } & $\begin{array}{c}\text { 4-Muito } \\
\text { Adequado }\end{array}$ & $\begin{array}{c}\text { 5-Bastante } \\
\text { adequado }\end{array}$ & $\%$ \\
\hline $\begin{array}{l}\text { Sistema } \\
\text { defensivo }\end{array}$ & $?$ & 2 & $100 \%$ \\
$\begin{array}{l}\text { Tipo de actuação } \\
\text { da defesa } \\
\text { Posto específico } \\
\text { do defensor }\end{array}$ & 2 & 1 & $100 \%$ \\
$\begin{array}{l}\text { Relação } \\
\text { numérica Def/At } \\
\text { no momento da } \\
\text { finalização }\end{array}$ & 5 & 2 & $73,8 \%$ \\
\end{tabular}

Analisada a relação do defensor com o atacante com bola, interessou-nos perceber a organização defensiva em que está inserido o referido defensor. As respostas obtidas demonstram que o sistema defensivo e o tipo de actuação da defesa, de forma unânime, e a relação numérica defesa/ataque são adequados para perceber o rendimento defensivo.

Quadro 10-Macro-categoria recuperação da bola.

\begin{tabular}{l|c|c|c}
\multicolumn{1}{c|}{ Indicador } & $\begin{array}{c}\text { 4-Muito } \\
\text { Adequado }\end{array}$ & $\begin{array}{c}\text { 5-Bastante } \\
\text { adequado }\end{array}$ & $\%$ \\
\hline Guarda -redes & 6 & 3 & $100 \%$ \\
Defensores & 1 & 8 & $100 \%$
\end{tabular}

No Andebol a recuperação da bola pode ser efectuada pelo guarda-redes e pelos jogadores de campo, e em cada um dos casos em diferentes situações:

(i) Através do guarda-redes, quando este defende o remate à baliza, dominando a bola ou enviando-a para além da linha final; quando o guarda-redes repõe em jogo a bola enviada pelos adversários directamente para além da linha final; ou ainda quando repõe a bola em jogo após a marcação de um livre assinalado pela dupla de arbitragem; (ii) Pelos jogadores de campo, quando estes ganham um ressalto defensivo, fazem bloco ao remate com sucesso, ganham a disputa da bola durante o drible do adversário, interceptam um passe, repõem a bola em jogo após falta sancionada ao atacante, ou quando repõem a bola a meio campo após golo sofrido.
As respostas obtidas quanto à adequação destes dois indicadores são significativas, bem como o facto de existirem diferenças no grau de adequação manifestado pelos especialistas. Ao ser considerado, por oito dos nove especialistas, bastante adequado o indicador recuperação da bola pelo defensor, contra apenas três que consideram bastante adequado o indicador recuperação da bola pelo guarda-redes, parece-nos clara a maior importância atribuída pelos especialistas à recuperação da bola pelos defensores na análise do rendimento.

Quadro 11 - Macro-categoria desenvolvimento da sequência ofensiva.

\begin{tabular}{|c|c|c|c|}
\hline Indicador & $\begin{array}{c}\text { 4-Muito } \\
\text { Adequado }\end{array}$ & $\begin{array}{l}\text { 5- Bastante } \\
\text { adequado }\end{array}$ & $\%$ \\
\hline $\begin{array}{l}\text { Zona onde se inicia a } \\
\text { sequência ofensiva }\end{array}$ & 2 & 4 & $66,7 \%$ \\
\hline Modo como se inicia & 4 & 2 & $66,7 \%$ \\
\hline Jogador que inicia & 4 & 0 & $44,4 \%$ \\
\hline Número de passes & 3 & 2 & $55,6 \%$ \\
\hline Número de jogadores & 5 & 2 & $77,8 \%$ \\
\hline $\begin{array}{l}\text { Número de } \\
\text { corredores utilizados }\end{array}$ & 4 & 3 & $77,8 \%$ \\
\hline $\begin{array}{l}\text { Duais os corredores } \\
\text { utilizados }\end{array}$ & 3 & 2 & $55,6 \%$ \\
\hline Método de jogo & 4 & 4 & $88,9 \%$ \\
\hline $\begin{array}{l}\text { Relação numérica } \\
\text { ataque/defesa }\end{array}$ & 3 & 4 & $77,8 \%$ \\
\hline $\begin{array}{l}\text { Duração da } \\
\text { sequência ofensiva }\end{array}$ & 6 & 1 & $77,8 \%$ \\
\hline Faltas sofridas & 3 & 2 & $55,6 \%$ \\
\hline $\begin{array}{l}\text { Sanções disciplinares } \\
\text { a favor }\end{array}$ & 5 & 2 & $77,8 \%$ \\
\hline "Time-out" pedidos & 4 & 0 & $44,4 \%$ \\
\hline $\begin{array}{l}\text { Resultado parcial no } \\
\text { início da sequência }\end{array}$ & 3 & 1 & $44,4 \%$ \\
\hline $\begin{array}{l}\text { Tempo jogo decorrido } \\
\text { no momento da } \\
\text { interrupção }\end{array}$ & 3 & 0 & $33,3 \%$ \\
\hline
\end{tabular}

Nesta macro-categoria aparece como mais adequado, para analisar o rendimento, o parâmetro método de jogo. Para os especialistas auscultados são também indicadores adequados para esta análise a zona $e o$ modo como se inicia a sequência ofensiva, o número de jogadores e de corredores utilizados, a relação numérica ataque/defesa, a duração da sequência bem como as sanções disciplinares a favor. 
Quadro 12 - Macro-categoria finalização.

\begin{tabular}{|c|c|c|c|}
\hline Indicador & $\begin{array}{c}\text { 4-Muito } \\
\text { Adequado }\end{array}$ & $\begin{array}{l}\text { 5- Bastante } \\
\text { Adequado }\end{array}$ & $\%$ \\
\hline $\begin{array}{l}\text { Local onde é } \\
\text { finalizada a } \\
\text { sequência }\end{array}$ & 3 & 4 & $77,8 \%$ \\
\hline $\begin{array}{l}\text { Meios tácticos que } \\
\text { antecedem a } \\
\text { finalização }\end{array}$ & 3 & 4 & $77,8 \%$ \\
\hline $\begin{array}{l}\text { Organização } \\
\text { defensiva da equipa } \\
\text { que se opõe à } \\
\text { sequência ofensiva }\end{array}$ & 5 & 3 & $88,9 \%$ \\
\hline $\begin{array}{l}\text { Organização } \\
\text { ofensiva da equipa } \\
\text { que realiza a } \\
\text { sequência ofensiva }\end{array}$ & 5 & 3 & $88,9 \%$ \\
\hline Modo de conclusão & 3 & 4 & $77,8 \%$ \\
\hline $\begin{array}{l}\text { Resultado do } \\
\text { marcador após a } \\
\text { sequência ofensiva }\end{array}$ & 2 & 4 & $66,7 \%$ \\
\hline
\end{tabular}

Contextualizar a finalização considerando o local onde ocorre, o que a antecedeu, a relação entre as organizações ofensiva e defensiva em confronto, o modo como se realizou e o resultado do marcador foi considerado adequado pelos peritos na análise do rendimento de uma equipa em competição.

Considerando todo o processo de elaboração do questionário, construído com base numa revisão alargada de bibliografia sobre análise do rendimento no Andebol, com o levantamento dos indicadores utilizados para esse fim em trabalhos científicos já realizados, e tendo em conta o perfil dos inquiridos tanto ao nível da sua formação científica como ao nível da sua experiência e formação profissional no âmbito do Andebol, considerámos suficiente o número de inquiridos, tendo valorizado a qualidade dos mesmos.

De acordo com este pressuposto, considerando o grau 3 como valor neutro e $66,5 \%$ como valor de corte, foram validados as seguintes macro-categorias e indicadores (ver Quadro 13):

Quadro 13. Macro-categorias e indicadores validados.

\begin{tabular}{|c|c|}
\hline Macro-categorias & Indicadores \\
\hline \multirow[t]{3}{*}{ Guarda-redes/Atacante com bola } & - Localização do atacante \\
\hline & - Acção do guarda-redes na defesa da baliza \\
\hline & - Colaboração guarda-redes/Defensor \\
\hline \multirow[t]{2}{*}{ Defensor / Atacante com bola } & - Posição do defensor \\
\hline & -Tipo de oposição \\
\hline \multirow[t]{3}{*}{ Critério Defensor /Organização Defensiva } & - Sistema defensivo \\
\hline & - Tipo de actuação defensiva \\
\hline & - Relação numérica defesa/ataque no momento da finalização \\
\hline \multirow[t]{2}{*}{ Critério Recuperação da bola } & - Guarda - redes \\
\hline & - Defensores \\
\hline \multirow[t]{8}{*}{ Critério Desenvolvimento } & -Zona de início da sequência \\
\hline & Modo como se inicia \\
\hline & -Número de jogadores \\
\hline & - Número de corredores utilizados \\
\hline & - Método de jogo \\
\hline & - Relação numérica ataque/defesa \\
\hline & - Duração da sequência \\
\hline & -Sanções disciplinares a favor \\
\hline \multirow[t]{6}{*}{ Critério Finalização } & - Local onde é finalizada a sequência \\
\hline & - Meios tácticos que antecedem a finalização \\
\hline & - Organização defensiva equipa que se opõe à sequência \\
\hline & - Organização ofensiva da equipa que realiza a sequência ofensiva \\
\hline & - Modo de conclusão \\
\hline & - Resultado marcador após a sequência ofensiva \\
\hline
\end{tabular}


Foram nove as categorias observáveis, ou indicadores, não validadas, de acordo com os critérios já acima descritos e utilizados no processo de validação:

- Macro-categoria guarda-redes/atacante com bola: Acção de remate

- Macro-categoria defensor/organização defensiva: Posto específico do defensor

- Macro-categoria desenvolvimento: Jogador que inicia a sequência; Número de passes; Quais os corredores utilizados; Faltas sofridas; "Time-out" pedidos; Resultado parcial no início da sequência; Tempo de jogo decorrido no momento da interrup̧̧ão.

\section{FINALIZAÇÃO DO PROCESSO DE ELABORAÇÃO DO SISTEMA}

Tratados e analisados os resultados, passou-se à depuração dos indicadores do instrumento de observação, bem como à inclusão, de indicadores propostos pelos especialistas.

Tendo em conta os objectivos do nosso estudo, a riqueza da informação que poderíamos perder relativa à interacção tempo de jogo/resultado do marcador/comportamentos observados e níveis de eficácia, bem como à opinião dos especialistas sobre a influência do tempo de jogo e do resultado nas eficácias ofensivas e defensivas, manifestadas na $1^{\text {a }}$ parte do questionário, decidimos manter o indicador "resultado parcial no início da sequência ofensiva" e acrescentar "tempo de jogo decorrido no início da sequência", como indicadores da macro-categoria "desenvolvimento".

Relativamente a outros indicadores a incluir no estudo, propostos pelos especialistas, apenas três dos nove questionados consideraram dever ser acrescentadas novos indicadores, apontando cada um deles, indicadores diferentes: a) Faltas técnicas; b) ressaltos defensivos; c) ressaltos ofensivos; d) número de vezes que a equipa perde a posse da bola sem finalizar; e) organização da sequência dos passes; f) variabilidade dos meios técnico- tácticos utilizados; g) resultado das sequências de posse de bola anteriores. Analisados os indicadores propostos e tendo em conta as possibilidades e objectivos do estudo, optámos por integrar os indicadores "ressaltos defensivos" e "ressaltos ofensivos" no "modo de recuperação da bola" na macro-categoria "recuperação da bola".
Considerando os indicadores existentes, suficientes para recolher a informação que permita analisar o "número de vezes que a equipa perde a posse da bola sem finalizar", o "resultado das sequências anteriores a cada sequência analisada" e as "faltas técnicas", estes aspectos serão tidos em conta no tratamento e análise dos dados.

Após validado o instrumento de observação, testámos a sua aplicação, realizando sessões de observação de jogos do Campeonato da Europa 2002, que nos conduziu ao aperfeiçoamento do sistema e que nos levou a introduzir ou corrigir alguns dos indicadores, desenvolvendo as macro- categorias que achámos carenciadas, beneficiando da flexibilidade do sistema misto de formato de campo com sistema de categorias (Ver quadro 14). 


\begin{tabular}{|c|c|c|}
\hline Macro - categorias & Indicadores [categorias observáveis] & Códigos \\
\hline Localização espacial & $\begin{array}{l}\text { - Baliza } \\
\text { - No Campograma }\end{array}$ & 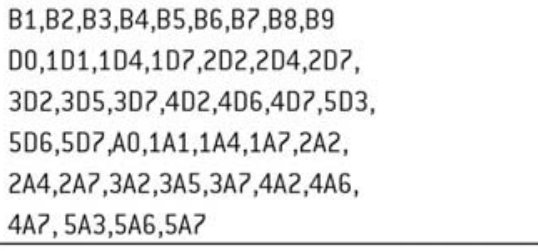 \\
\hline $\begin{array}{l}\text { Guarda-redes/ } \\
\text { Atacante com bola }\end{array}$ & $\begin{array}{l}\text { - Localização do atacante } \\
\text {-Acção do guarda-redes: } \\
\text { - Sai em contacto com solo } \\
\text { - Sai e salta em leque } \\
\text { - Sai e baixa-se } \\
\text { - Baixa-se } \\
\text { - Defende com as duas mãos } \\
\text { - Defende com um braço/mão } \\
\text { - Defende com perna/pé } \\
\text { - Defende com perna/ braço } \\
\text { Colaboração com defensor: } \\
\text { - Colocado em linha com defensor } \\
\text { - Antecipa ângulo curto } \\
\text {-Antecipa ângulo comprido }\end{array}$ & $\begin{array}{l}\text { Referida ao campograma } \\
\text { Sap } \\
\text { SL } \\
\text { SC } \\
\text { Bx } \\
\text { Ms } \\
\text { Br } \\
\text { Per } \\
\text { BP } \\
\text { Def } \\
\text { Act } \\
\text { Acp }\end{array}$ \\
\hline Defensor/Atacante com bola & $\begin{array}{l}\text { - Posição do defensor: } \\
\text {-Afastado na linha da bola } \\
\text { - Afastado na linha do atacante } \\
\text { - Próximo na linha da bola } \\
\text { - Próximo na linha do atacante } \\
\text { - Tipo de oposição: } \\
\text {-Passiva: - Parado } \\
\text { - Deslocamento lateral } \\
\text {-Activa: - Faz bloco } \\
\text { - Aproxima-se } \\
\text { - Contacta }\end{array}$ & $\begin{array}{l}\text { ALb } \\
\text { ALat } \\
\text { PLb } \\
\text { PLat } \\
\text { Stop } \\
\text { Desl } \\
\text { BI } \\
\text { Apr } \\
\text { Cont }\end{array}$ \\
\hline $\begin{array}{l}\text { Defensor/ } \\
\text { Organização Defensiva }\end{array}$ & $\begin{array}{l}\text {-Sistema defensivo } \\
\text { - Tipo de actuação defensiva: } \\
\text {-Zona activa } \\
\text { - Zona passiva } \\
\text { - Pressing } \\
\text { - Recuperação defensiva activa } \\
\text { - Recuperação defensiva passiva } \\
\text { - Relação numérica defesa/ataque }\end{array}$ & $\begin{array}{l}3: 3,4: 2,5: 1,6: 0,3: 2: 1,1: 5,5+1,4+2, \mathrm{H} \times \mathrm{H} \text {, } \\
4: 1,5: 0,1: 4, \text { RDXDT } \\
\text { ZA } \\
\text { ZP } \\
\text { Press } \\
\text { RDA } \\
\text { RDP } \\
6 \times 6,6 \times 5,5 \times 5,5 \times 6,6 \times 4,4 \times 6,5 \times 4,4 \times 5\end{array}$ \\
\hline Recuperação da bola & $\begin{array}{l}\text { Guarda-redes: } \\
\text { - Defende e controla a bola } \\
\text { - Defende sem controlar a bola } \\
\text { - Recupera a bola sem defesa } \\
\text { - Intercepta a bola } \\
\text { - Faz reposição bola após falta assinalada }\end{array}$ & $\begin{array}{l}\text { Dcb } \\
\text { Dsc } \\
\text { Rec } \\
\text { Int } \\
\text { F }\end{array}$ \\
\hline
\end{tabular}




\begin{tabular}{|c|c|c|}
\hline & $\begin{array}{l}\text { Defensores: } \\
\text { - Intercepção da bola } \\
\text { - Bloco ao remate } \\
\text { - Ressalto defensivo } \\
\text { - Ressalto ofensivo } \\
\text { - Desarme } \\
\text { - Recuperação após falta atacante } \\
\text { - Recuperação após falha técnica adversário } \\
\text { - Após a equipa sofrer golo } \\
\text { Início da sequência: } \\
\text { Zona de início: } \\
\text { - Local de início } \\
\text { Modo de início: } \\
\text { - Passe curto lateral } \\
\text { - Passe curto em frente } \\
\text { - Passe curto para trás } \\
\text { - Passe longo } \\
\text { - Drible } \\
\text { - Passe em salto curto } \\
\text { - Passe em salto longo } \\
\text { № de jogadores } \\
\text { No de corredores utilizados } \\
\text { Método de jogo: } \\
\text { - Contra-ataque simples } \\
\text { - Contra-ataque apoiado } \\
\text { - Ataque organizado } \\
\text { Duração da sequência }\end{array}$ & $\begin{array}{l}\text { I } \\
\text { BLR } \\
\text { Res } \\
\text { R0 } \\
\text { Ds } \\
\text { FA } \\
\text { FT } \\
\text { AG } \\
\text { Referida ao campograma } \\
\text { Pcl } \\
\text { Pcf } \\
\text { Pct } \\
\text { PI } \\
\text { Dr } \\
\text { Ps } \\
\text { PsI } \\
\text { U, D, T, 0, C, S } \\
\text { 1,2,3,4,5 } \\
\text { CA } \\
\text { Cap } \\
\text { A0 } \\
\text { Tempo em segundos [00"] }\end{array}$ \\
\hline Desenvolvimento & $\begin{array}{l}\text { Sanções disciplinares a favor } \\
\text { Tempo de jogo decorrido } \\
\text { no início da sequência } \\
\text { Resultado parcial no início } \\
\text { Resultado do marcador no final da sequência }\end{array}$ & $\begin{array}{l}\text { Adv, 2', Desq, Exp } \\
\text { Registado em minutos e segundos (00'00"] } \\
0-0,1-0,0-1,2-0,0-2,3-0,0-3,4-0,0-4,5-0 \text {, } \\
0-5 \\
\text { Resultado do marcador }\end{array}$ \\
\hline Finalização & $\begin{array}{l}\text { Local onde é finalizada } \\
\text { Meios tácticos: } \\
\text { - Um contra um } \\
\text { - Passe picado } \\
\text { - Passe de ruptura } \\
\text { - Entrada } \\
\text { - Bloqueio } \\
\text { - Cruzamento } \\
\text {-Écran } \\
\text { - Penetrações sucessivas } \\
\text { Organização defensiva } \\
\text { Organização ofensiva } \\
\text { Modo de conclusão: }\end{array}$ & $\begin{array}{l}\text { Referida ao campograma } \\
1 \times 1 \\
\text { PP } \\
\text { PR } \\
\text { EN } \\
\text { B } \\
\text { CR } \\
\text { E } \\
\text { PS } \\
3: 3,4: 2,5: 1,6: 0,3: 2: 1,1: 5,5+1,4+2, \mathrm{H} \times \mathrm{H}, \\
4: 1,5: 0,1: 4, \mathrm{RD} \times \mathrm{DT} \\
3: 3,2: 4,3: 3-2: 4\end{array}$ \\
\hline
\end{tabular}




\begin{tabular}{|l|l} 
Com remate & \\
- Golo & G \\
- Defesa do guarda-redes & DGR \\
- Remate para fora & RF \\
- Remate ao poste/ trave & RP \\
- Remate contra bloco & RB \\
- Golo de ?m & G? \\
- Defesa do guarda-redes a livre de $7 \mathrm{~m}$ & DGR? \\
Sem remate & \\
- Violação da área de baliza & V \\
- Falta do ataque & Fat \\
- Mau passe/ má recepção & MP \\
- Desarme & PB \\
- Intercepção da bola & IN
\end{tabular}

\section{SÍNTESE CONCLUSIVA}

Ao propormos a realização de um estudo dos factores táctico-técnicos de rendimento no jogo de Andebol e a análise da sua influência no resultado final, optámos pela utilização da metodologia observacional, como método científico mais adequado aos objectivos do estudo, dado que possibilita a recolha de dados e seu tratamento, através da análise sequencial e da técnica de coordenadas polares. Assim sendo, colocou-se-nos a necessidade de encetar os passos de elaboração e validação do sistema de observação a utilizar na recolha dos dados a partir da amostra.

Face à grande diversidade de situações e comportamentos que ocorrem durante as sequências ofensivas do jogo de Andebol, optámos pela construção de um sistema misto de formato de campo e sistemas de categorias, dada a sua não estandardização e a sua maior flexibilidade.

Através de uma pesquisa bibliográfica, efectuámos um levantamento dos indicadores utilizados em diferentes estudos, realizados no âmbito da análise do rendimento no Andebol. Consultando diferentes manuais de treino da modalidade $(9,10,19,22,24)$, analisámos também a importância atribuída, aos diferentes factores do treino do Andebol.

Iniciámos a construção do sistema de observação através do estabelecimento dos eixos fundamentais (as macro-categorias), sobre os quais se desenvolveria o formato de campo, baseados nos objectivos a alcançar no nosso trabalho.
Passámos de seguida à fase exploratória do estudo, através da observação não sistemática de gravações vídeo de jogos referentes ao Campeonato da Europa de Andebol de 2002 e Campeonato do Mundo de Andebol 2003. Esta fase exploratória permitiu-nos efectuar uma listagem não fechada de condutas/ situações observadas e correspondentes a cada uma das macro-categorias. Esta fase exploratória foi considerada concluída quando em duas observações consecutivas não registámos novas condutas/situações. Com os dados obtidos pudemos construir o sistema misto de formato de campo e sistemas de categorias, passando a seguir para a validação do mesmo. O procedimento de validação adoptado foi a realização de um questionário, recorrendo para o efeito, a um grupo de peritos em Andebol: treinadores das Ligas de Andebol de Portugal e investigadores das Ciências do Desporto - da área do rendimento desportivo/Andebol.

Depois de redigido o questionário, realizámos um pré-teste no sentido de avaliar a validade e precisão do mesmo, tendo seleccionado para o efeito, treinadores de Andebol, antigos praticantes, licenciados em Educação Física e Desporto, com a opção de Andebol. Logo que concluídos o questionário e o pré-teste, procedeu-se à respectiva reformulação, tendo em conta as opiniões e dificuldades sentidas pelos inquiridos, após o que se considerou o mesmo validado. Por fim, o questionário foi distribuído aos especialistas, não sem antes os contactarmos para solicitarmos a sua colaboração, bem como para explicarmos 
e prestarmos todos os esclarecimentos a propósito do mesmo e dos objectivos do trabalho.

A escala de Likert, de cinco pontos foi a graduação adoptada no questionário que aplicámos.

Após a recolha dos questionários, procedemos ao tratamento e análise dos resultados obtidos, tendo utilizado como valor de corte para validar os diferentes indicadores $>65 \%$. Tal valor foi convencionado por corresponder a seis dos nove especialistas inquiridos, ou seja metade mais um do total, consideradas as respostas situadas nos níveis quatro e cinco da escala de Likert, já que o nível três foi considerado um valor neutro.

Consideraram-se então validados pelos especialistas, e de acordo com os critérios acima mencionados, os indicadores: (i) Referentes à análise do rendimento do guarda-redes: localização do atacante, aç̧ão do guarda-redes na defesa da baliza, colaboração guardaredes/defensor; (ii) Referentes à análise do rendimento defensivo: posição do defensor, tipo de oposição, sistema defensivo, tipo de actuação defensiva, relação numérica defesa/ataque no momento da finalização; (iii) Referentes à análise do rendimento na recuperação da bola e início da sequência ofensiva: recuperação da bola pelo guarda-redes, recuperação da bola pelos defensores, zona de início, modo como se inicia; (iv) Referentes à análise do rendimento durante o desenvolvimento da sequência ofensiva: número de jogadores, número de corredores utilizados, método de jogo, relação numérica ataque/defesa, duração da sequência, sanções disciplinares a favor; (v) Referentes à análise do rendimento na finalização: local de finalização, meios tácticos que antecedem a finalização, organização defensiva da equipa que se opõe à sequência ofensiva, organização ofensiva da equipa que realiza a sequência ofensiva, modo de conclusão, resultado do marcador após a sequência.

$\mathrm{O}$ instrumento que aqui descrevemos será utilizado na recolha de dados relativos a um estudo que irá desenvolver-se nos próximos meses e cujo tema é: "Factores táctico-técnicos de rendimento no jogo de Andebol de Alto Nível mundial. Estudo da sua influência no resultado final".

\section{Agradecimento}

Este estudo foi realizado no âmbito do trabalho de doutoramento, com o apoio do CITMA (Centro de Ciência e Tecnologia da Madeira).

\section{CORRESPONDÊNCIA \\ João Prudente}

Departamento de Educação Física e Desporto

Universidade da Madeira

Campus Universitário da Penteada

9000-390 Funchal, Portugal

prudente@uma.pt 


\section{REFERÊNCIAS BIBLIOGRÁFICAS}

1. Anguera, M.T. (1988). Observación en la escuela. Barcelona:Graó.

2. Anguera, M.T. (1990). Metodología observacional. In J. Arnau, M.T. Anguera y J.Gómez. Metodología de la investigación en Ciencias del Comportamiento Murcia: Secretariado de Publicaciones de la Universidad de Murcia, 125-236.

3. Anguera, M.T. (2000). Del registro narrativo al análisis cuantitativo: Radiografía de la realidad perceptible. In Ciencia $i$ cultura en el segle XXI. Estudis en homenatge a Josep Casajuana. Barcelona: Reial Academia de Doctors, 41-71.

4. Anguera, M.T. (2003). Metodología básica de observación en fútbol. In T. Ardá (Coord.), Metodología de la enseñanza del fútbol. Barcelona: Paidotribo, 303-324.

5. Anguera, M.T. \& Blanco, A. (2003). Registro y codificación en el comportamiento deportivo. In A. Hernández Mendo (Coord.), Psicología del Deporte (Vol. 2). Metodología (p. 634). Buenos Aires: Efdeportes (www.efdeportes.com).

6. Anguera, M. T.; Blanco, A.; Losada, J. \& Hernández Mendo, A. (2000). La metodologia observacional en el deporte: conceptos básicos. Lecturas: Educación Física y Deportes, 5(24). (http://www.efdeportes.com/efd24b/obs.htm). [2001, 19-03-2001].

7. Anguera, M. T \& Hernández Mendo, A. (1997). Aportaciones del analisis de coordenadas polares a los deportes de equipo. Paper presented at the VII Congresso Nacional de Psicologia del Deporte, Las Palmas de Gran Canarias.

8. Barbosa, J. A. (1999). A organização do jogo em Andebol Estudo comparativo do processo ofensivo em equipas de Alto Nivel, em função da relação numérica ataque - defesa. Dissertação de Mestrado, Universidade do Porto, Porto.

9. Garcia, J.A. (1989) La importância de las situaciones en desigualdad numérica, a la luz de un estúdio analítico de la alta competición. III Jornadas de Especialidades Deportivas. Perfeccionamento para entrenadores de Balonmano, Junta de Andalucía, UNISPORT, Málaga.

10. Garcia, J.A. (1994) Balonmano: Metodologia y alto rendimiento. Barcelona. Editora Paidotribo

11. Garganta, J. (1997). Modelação táctica do jogo de futebol. Estudo da organização da fase ofensiva em equipas de alto rendimento. Tese de Doutoramento, Universidade do Porto, Porto.

12. Garganta, J. (1998). Analisar o jogo nos Jogos Desportivos Colectivos: Uma preocupação comum ao Treinador e ao Investigador. Horizonte, XIV (83), 7-14.

13. Garganta, J. (2000). O treino da táctica e da estratégia nos jogos desportivos. In J. Garganta (Ed.), Horizontes e Órbitas no treino dos Jogos Desportivos. Porto: Universidade do Porto, Faculdade de Ciências do Desporto e de Educação Física, Centro de Estudos dos Jogos Desportivos.

14. Gil, A. C. (1994). Métodos e técnicas de pesquisa social. (4a ed.). S.Paulo: Editora Atlas.

15. Hernández Mendo, A. \& Molina, M. (2002). Como usar la observación en la psicologia del deporte: princípios metodológicos. Lecturas: Educación Física y Deportes, 8(49). (http://www.efdeportes.com/efd49/obs.htm). [2002, 1006-2002].

16. Hernández Mendo, A.; Ramos, R. (1996). Introducción a la informática aplicada a la psicología del deporte. Herramientas informáticas de uso en las ciencias del deporte. Madrid: Ra-Ma.

17. Heil, J. \& Henschen, K. (1997). Assessment in sport and exercise psychology. In J.L.Van Raalte \& B.W. Brewer
(Eds.) Exploring sport and exercise psychology. Washington, D.C.: American Psychological Association, 229-255.

18. Hughes, M. \& Bartlett, R. (2002). The use of performance indicators in performance analysis. Journal of Sports Sciences (20), 739-754

19. Konzag, I.; Stein, H.; Müller, M. (1996). Balonmano. Entrenarse Jugando. El sistema de ejercicios complete. Barcelona. Editora Paidotribo.

20. Lames, M. \& Hansen, G. (2001). Designing observational systems to suport top-level teams in game sports. Paper presented at the World Congress of performance analysis, sport science and computers.

21. Oliveira, C.; Campaniço, J. \& Anguera, M.T. (2001). La metodologia observacional en la enseñanza elemental de la natación: el uso de los formatos de campo. Metodologia de las Ciencias del Comportamiento, 3 (2), 267-282.

22. Sánchez, F. (1991). Analisis del Contenido del Juego. In J. G. Cuesta, (Ed.). Balonmano. Madrid: Federation Española de Balonmano e Comité Olímpico Español.

23. Silva, J. A. (1998). Análise dos indicadores de rendimento em equipas de Andebol. Comunicação apresentada no IV World Congress of Notational Analysis of Sport. Universidade do Porto, Faculdade de Ciências do Desporto e de Educação Física.

24. Seco, J.D.R. (1998). Los XI Campeonatos del mundo Júnior Turquia 1997. Comunicação apresentada no II Seminário Internacional. Córdoba 98, Córdoba. 